\title{
A Macroeconomic Consequence of Foreign Direct Investment: The Welfare Economics of Industrial Hollowing
}

\author{
Masayuki Otaki \\ Institute of Social Science, University of Tokyo, Tokyo, Japan \\ Email: ohtaki@iss.u-tokyo.ac.jp
}

Received June 21, 2012; revised July 20, 2012; accepted August 17, 2012

\begin{abstract}
This article considers macro and welfare economic implications concerning foreign direct investment under a flexible exchange rate system. There are serious conflicts between foreign-invested firms and their home country as a whole. Although lower wages incentivize firms to obtain foreign direct investment, such a movement harms the welfare of the home-country's economy in the following ways. First, an increase in unemployment in the home country worsens the economy's welfare as proved by Otaki [1]. Second, an appreciation in the real exchange rate, which is induced by the transfer of earned profits in foreign countries to the home country, reduces the value of profits in terms of domestic goods. We prove that such an appreciation entirely cancels the benefit from the cost reduction that originates from the foreign direct investment in lower-wage countries. In the end, only the downturn in employment circumstance remains. In this sense, the glut of foreign direct investment is harmful and, some coordination is required between firms and the government of the home country.
\end{abstract}

Keywords: Macroeconomics of Foreign Direct Investment; Industrial Hollowing; Exchange Rate Appreciation; Leakage of Effective Demand

\section{Introduction}

Although, according to the neoclassical trade theory that deals with a barter economy under perfect competition, it seems natural and efficient for a higher-wage and capital-abundant country to export her real capital, such conventional wisdom cannot apply to a monetary economy in which idle resources (specifically labor forces) are prevalent even if every price adjusts flexibly, as proved by Otaki [1-3]. Based on Otaki [4], this article analyzes the macro and welfare economic consequences of foreign direct investment of a small and monetary economy under a flexible exchange rate system.

There are numerous discussions concerning foreign direct investment. Caves [5] argues that foreign direct investment involves a bundle of capital, technology, and management skills. Hood and Young [6] and Caves [7] regard multi-national company as a device of internalizeing such firm-specific skills via economizing various transaction costs. However, these discussions stay in analyses concerning the behavior of each individual firm. There is no guarantee that higher efficiency within individual firms leads to enhance social welfare of the nation as a whole, specifically in the dynamic monetary economy ${ }^{1}$.
Foreign direct investment causes serious conflicts between capital-exporting firms and their home country. Such conflicts come from the fact that the foreign direct investment deprives the home country of employment opportunities and reduces the effective demand in the home country. Such a process is cumulative and self-enforcing ${ }^{2}$.

In addition, lower-wage countries, where employees are not well-associated and do not have the wage-bargaining power against their employer, ceteris paribus, attracts foreign direct investment seeking more profits. However, under the flexible exchange rate system, the transfer of earned profits to the home country appreciates the real exchange rate, as long as savings in the home country are insensitive to the real exchange rate.

\footnotetext{
${ }^{1}$ Applying the two by two model of the barter economy, MacDougall [8] and Kemp [9] proved that if a capital-exporting country is large enough to manipulate the interest rate via controlling the volume of exported capital, she can gain additional welfare. This is an application of the optimal tariff theorem. Such discussions belong to a quite different context from our theory that deals with the monetary economy characterized by the flexible exchange rate.

${ }^{2}$ Kahn [10] carefully distinguishes the home investment from the foreign direct investment, when he calculates the employment multiplier. His discussion clearly indicates that an opposite effect to the home economy's employment exists in these two capital investments.
} 
Thus, the additional profits that are sent from the lowerwage country are entirely absorbed by such an appreciation.

This phenomenon is a type of fallacy of composition. That is, although the real exchange rate is an exogenous variable for each firm, it is endogenous for the home country as a whole, and it is realigned by the synchronized profits transfer of foreign direct invested firms. Accordingly, as long as domestic savings are insensitive to the real exchange rate, the social benefits of foreign direct investment are absorbed by the appreciation of the exchange rate.

In sum, the stagnant and cumulative effect of foreign direct investment remains only in the home country. Such investment increases unemployment and results in a reduction of the effective demand among other effects. We shall prove that such economic consequences worsen the resource allocation of the home country in the sense of Pareto. That is, differing from the classical barter economy, industrial hollowing is a serious problem in the monetary economy.

The structure of this paper is as follows. In Section 2, we construct a macroeconomic model of a small open country in which the international movement of real capital is perfect (without any restriction). Section 3 addresses the welfare implication of foreign direct investment. Section 4 contains brief concluding remarks.

\section{The Model}

\subsection{The Structure of the Model}

We consider a small open economy under a flexible exchange rate system based on a standard two-periods overlapping generations (OLG) model. The world economy consists of two economies: the home country and the foreign country. The home country is very small relative to the foreign country and the behavior of the homecountry's industries never affects its counterpart's economic conditions, such as the real GNP.

The home country has two industries: the mobile and tradable industry (industry a) which can freely change its location and the immobile and non-tradable industry (industry $b$ ). Each industry consists of differentiated goods within the interval $[0,1]$. Each firm monopolistically produces its differentiated good. The technology is identical for all firms regardless of the country or Industry to which each belongs. A unit labor produces a unit good. That is, the labor productivity is assumed to be unity for all firms. Furthermore, individuals can participate with work only when he/she is young.

There is an asymmetry in the nominal wage determination. In the home country, the nominal wage is determined by the following two-step game developed by
Otaki [1]. In the first stage, each employer decides its pricing strategy and employment policy to maximize its profits. The second stage determines the nominal wage in accordance with the asymmetric Nash bargaining solution between the employer and his ensured employees.

In the foreign country, there is no bargaining power for employees, and the nominal wage keeps to the minimum reservation level. Thus, seeking more profit, all firms belonging to the mobile and tradable industry (industry a) move their factories to the foreign country as soon as international capital movement is permitted. This is the definition of industrial hollowing in our model. Furthermore, for simplicity, we assume that the foreign country is unable to produce good $a$. In addition, since every good is differentiated, a firm can segregate the domestic and foreign markets, and thus, a price discrimination policy is possible. This fact implies that the purchasing power parity theory never holds concerning exchange rate determination.

Finally, for simplicity, both governments keep the real money supply constant. Seigniorage is consumed by both industries $(a$ and $b)$ in the same proportion as in the private sectors.

\subsection{Optimization Problems of Economic Agents}

\subsubsection{Individuals}

We assume that every individual has the following utility function.

$$
\begin{aligned}
u\left(c_{1}, c_{2}\right) & \equiv\left[c_{1}\right]^{c}\left[c_{2}\right]^{1-c}-\delta \alpha, \\
c_{i} & \equiv\left[c_{a i}\right]^{\frac{1}{2}}\left[c_{b i}\right]^{\frac{1}{2}}, \\
c_{k i} & \equiv\left[\int_{0}^{1}\left[c_{k i}(z)\right]^{1-\eta^{-1}} \mathrm{dz}\right]^{\frac{1}{1-\eta^{-1}},} \\
& 1>c>0, \eta>1,
\end{aligned}
$$

where $c_{i}$ denotes the aggregate consumption during the $i$ th stage of life, $c_{k i}$ is the aggregate consumption of industry k's goods during the ith stage of life, and $c_{k i}(z)$ is the consumption of good $z$ that belongs to industry k. $a$ is the disutility of labor, and $\delta$ is a definition function that takes the value unity when employed and zero when unemployed.

To solve this optimization problem, we need three steps. First, given the expenditure of $k$ industry's goods $y_{k i}(k=a$ or $b)$, we maximize $c_{k i}$ with respect to $c_{k i}(z)$. As the second step, since $c_{k i}$ becomes a function of $y_{k i}$, we need to maximize

$$
c_{i} \equiv\left[c_{a i}\left(y_{a i}\right)\right]^{\frac{1}{2}}\left[c_{b i}\left(y_{b i}\right)\right]^{\frac{1}{2}}
$$

with respect to $y_{k i}$ under the given total real spending during period $i, y_{i}$. 
The final step is the maximization of

$$
\left[c_{1}\left(y_{1}\right)\right]^{c}\left[c_{2}\left(y_{2}\right)\right]^{1-c}
$$

with respect to $y_{i}$ under the lifetime budget constraint.

The first step leads us the following demand function:

$$
\begin{aligned}
c_{k i}(z) & =\left[\frac{p_{k i}(z)}{P_{k i}}\right]^{-\eta} y_{k i}, \\
P_{k i} & \equiv\left[\int_{0}^{1}\left[p_{k i}(z)\right]^{1-\eta} \mathrm{d} z\right]^{\frac{1}{1-\eta}}, y_{k i} \equiv \frac{\mathrm{Y}_{k i}}{P_{k i}},
\end{aligned}
$$

where $y_{k i}$ is the nominal expenditure for goods $k$. Since the equilibrium is symmetric, without the loss of generality, we can set

$$
P_{i} \equiv P_{a i}=P_{b i}, \forall i .
$$

Hence, the second step of the maximization becomes

$$
\begin{aligned}
& \max _{y_{k i}}\left[y_{a i}\right]^{\frac{1}{2}}\left[y_{b i}\right]^{\frac{1}{2}}, \\
& \text { s.t. } y_{i}=y_{a i}+y_{b i}, y_{i} \equiv \frac{Y_{i}}{P_{i}} .
\end{aligned}
$$

The solution is

$$
y_{a i}=y_{b i}=\frac{y_{i}}{2} .
$$

By using (3), the final maximization is expressed by

$$
\begin{aligned}
& \max _{Y_{i}}\left[y_{1}\right]^{c}\left[y_{2}\right]^{1-c}, \\
& \text { s.t. } y_{1}+\rho y_{2}=y, y \equiv \frac{Y}{P_{1}}
\end{aligned}
$$

where $y$ is the nominal income earned when the employee is young, and $\rho$ is the inflation rate. Equation (4) leads us to the Keynes' type aggregate consumption of the young generation. That is,

$$
y_{1}=c \cdot y \text {. }
$$

Substituting Equation (5) and the lifetime budget constraint into Equation (4), we obtain the following indirect utility function concerning the consumption stream:

$$
\begin{aligned}
I U\left(P_{1}^{l}, P_{2}^{l}, Y^{l}\right) & \equiv \frac{A Y^{l}}{\left[P_{1}^{l}\right]^{c}\left[P_{2}^{l}\right]^{1-c}} \\
& =A\left[\rho_{l}\right]^{-[1-c]} y^{l}, A \equiv c^{c}[1-c]^{1-c} .
\end{aligned}
$$

The superscript $l(l=h, f)$ denotes the home and foreign country. From Equation (6), we obtain the nominal reservation wage $W_{t}^{R l}$ during period $t$ as

$$
W_{t}^{R l}=A^{-1} P_{t}^{l}[\rho]^{1-c} \alpha \text {. }
$$

\subsubsection{Employers}

It is clear from Equations (2) and (3) that every firm be- longing to industry $a$ faces the identical demand function

$$
c_{a t}^{h}(z)=\left[\frac{p_{t}^{h}(z)}{P_{t}^{h}}\right]^{-\eta} \frac{y_{t}^{h}}{2}, c_{a t}^{f}(z)=\left[\frac{p_{t}^{f}(z)}{P_{t}^{f}}\right]^{-\eta} \frac{y_{t}^{f}}{2}
$$

where $c_{a t}^{l}(l=h, f)$ is the demand for good $a$ within the home and foreign country, respectively. $y_{t}^{l}(l=h, f)$ denotes the real effective demand of country $l$ during period $t$. In addition, let us define the real exchange rate $e_{t}$ by

$$
e_{t} \equiv \frac{E_{t} P_{t}^{f}}{p_{t}^{d}}
$$

where $E_{t}$ is the nominal exchange rate.

We regard the production-wage determination as the following two-stage game developed by Otaki [1]. First, an employer determines the employment and price level so as to maximize its profits. Second, an employer and a certain member of individuals, who have been ensured employment, negotiate the nominal equilibrium wage in accordance with the asymmetric Nash bargaining solution of which the threaten point is $\left(0, W^{R}\right)$.

Since the production function is linear, we can separate a firm's profit maximization into the domestic and foreign markets. Since these problems are essentially identical, for avoiding the duplication of elementary calculation, we confine ourselves to the domestic market problem.

Let us denote as $\theta$ the bargaining power of an employer. Then the equilibrium nominal wage of industry $a$ in the domestic labor market is determined as

$$
W_{a t}^{h^{*}}=\theta W_{t}^{R h}+[1-\theta] p_{a t}^{h}(z) .^{3}
$$

By following Equation (9), the profit function of each firm within industry a is represented by

$$
\pi_{a t}^{h}(z)=\theta\left[p_{a t}^{d}(z)-W_{t}^{R h}\right] c_{a t}^{h}(z) .
$$

Maximizing (10) with respect to $p_{a i}^{h}(z)$, we obtain the following optimal-pricing rule concerning the domestic market regardless of the strength of the bargaining power $\theta$,

$$
p_{a t}^{h^{*}}(z)=\frac{W_{t}^{R h}}{\left[1-\eta^{-1}\right]}, \forall t, z .
$$

Thus, every firm offers the same price regardless of the industry to which it belongs.

In the foreign country market, we obtain the optimalpricing rule via the same procedure as

$$
p_{a t}^{f^{*}}(z)=\frac{W_{t}^{R f}}{\left[1-\eta^{-1}\right]}, \forall t, z .
$$

Combining Equations (11) and (12) with (7), we ob-

${ }^{3}$ For the precise procedure for solving this bargaining problem, see Otaki [1]. 
tain the world-common equilibrium inflation rate $\rho^{*}$ as

$$
\rho^{*}=\left[\frac{\left[1-\eta^{-1}\right] A}{\alpha}\right]^{\frac{1}{1-c}} .
$$

Substituting Equations (11) and (12) into (10), the equilibrium aggregate profit function

$$
\frac{\pi_{a t}^{*}}{P_{t}^{h^{*}}}
$$

is obtained as

$$
\frac{\pi_{a t}^{*}}{P_{t}^{h^{*}}}=\frac{\eta^{-1}}{2}\left[\theta y_{t}^{h}+e_{t} y_{t}^{f}\right]
$$

It is apparent from Equation (14) that all factories belonging to the mobile industry $a$ move from the home country where $1>\theta>0$, to the foreign country where $\theta=1$. We define such an international capital movement as industrial hollowing.

\subsection{Market Equilibrium}

\subsubsection{The Foreign Exchange Market}

From the property of the OLG model without bequest motive, the domestic savings for foreign currency should be always equal to the sum of the expenditure of the foreign old generation and the government toward industry a plus the wage payments to foreign employees who work in industry $a$.

Thus, the equilibrium condition for the foreign exchange in the stationary state is

$$
\frac{1}{2}[1-c]\left[y^{h}-\frac{E_{i} W_{i}^{R}}{p_{i}^{a^{*}}} y^{a}\right]=\frac{\eta^{-1} e y^{f}}{2} .
$$

where $y^{a}$ is expressed as

$$
y^{a}=\frac{y^{h}+e y^{f}}{2} .
$$

The left-hand side of Equation (15), is the net foreign currency savings of the home country. The right-hand side of this equation is the sum of profits earned in the foreign country.

In addition, from Equation (11), we obtain

$$
\frac{E_{i} W_{i}^{R}}{p_{i}^{a}}=\left[1-\eta^{-1}\right]
$$

Substituting Equations (16) and (17) into (15) and rearranging the terms, we finally obtain the following equation concerning the equilibrium condition for the foreign exchange market:

$$
\left[\frac{[1-c] \eta^{-1}}{2}\right] y^{h}=\left[\frac{[1-c]+c \eta^{-1}}{2}\right] e y^{f} .
$$

\subsubsection{The Aggregate Goods Market}

Next we examine the aggregate goods market. The equilibrium condition is defined as

$$
\begin{aligned}
y^{h}= & c\left[y^{h}-\frac{E_{i} W_{i}^{R}}{p_{i}^{a}} y^{a}\right]+m \\
& +\frac{1}{2}\left[[1-c]\left[1-\frac{E_{i} W_{i}^{R}}{p_{i}^{a}} y^{f}\right]-\eta^{-1} e y^{f}\right]
\end{aligned}
$$

where $y^{h}\left(\equiv y^{a}+y^{b}\right)$ is the home country's real GNP (not GDP) in terms of the price of $a$ (mobile) industry's goods. The terms in the first bracket of the RHS of the above equation express the total consumption of the younger generation in the home country. Note that we must deduct the real wage payments

$$
\frac{E_{i} W_{i}^{R}}{p_{i}^{a}} y^{a}
$$

to the foreign country from the real GNP $y^{k}$ to calculate the real disposable income.

The second term is the sum of the government's and the older generation's expenditures in terms of the home currency $^{4}$. The terms in the second bracket correspond to the home-country's current account surplus.

$$
\frac{1-c}{2}\left[y^{h}-\frac{E_{i} W_{i}^{R}}{p_{i}^{a}} y^{a}\right]
$$

is the real export of the home-country firms (the surplus of trade balance).

$$
\frac{\eta^{-1}}{2} e y^{f}
$$

represents the surplus of the capital account.

Since there is no asset-accumulation motive in this model, the terms inside the second bracket takes value zero, as indicated by Equation (15). Accordingly, combining with (16) and (19), the aggregate goods market is cleared when

$$
y^{h}=c\left[y^{h}-\left[1-\eta^{-1}\right] y^{a}\right]+m .
$$

By using Equation (15), (20) can be rewritten as

$$
\begin{aligned}
y^{h} & =c\left[y^{h}-\left[1-\eta^{-1}\right] \frac{y^{h}+e y^{f}}{2}\right]+m \\
& =c\left[\frac{1+\eta^{-1}}{2}\right] y^{h}-\frac{1-\eta^{-1}}{2} e y^{f}+m .
\end{aligned}
$$

To summarize, we have two endogenous variables $\left(y^{h}, e\right)$ and two structural Equations (14) and (20) with

\footnotetext{
${ }^{4}$ We here assume that domestic money is credible in the sense of Otaki [4], and that the current prices are not affected by a change in the nominal money supply. Furthermore, the nominal money supply obeys the rule that the real money supply $m$ is kept constant. That is, the government's budget constraint is $\left[1-\rho^{-1}\right] m=g \cdot g$ is the real wasteful government expenditure.
} 
two exogenous variables $\left(m, y^{f}\right)$. Thus, the model is closed. Substituting (18) in to (21) and solving on $y^{h}$, we obtain

$$
y^{h}=\frac{m}{1-\frac{1}{2}\left[c\left[1+\eta^{-1}\right]-\frac{[1-c]\left[1-\eta^{-1}\right]}{1-c+c \eta^{-1}}\right]} .
$$

From (18) and (22), we can also ascertain $\frac{d e}{d m}>0$.

\section{Welfare Implications of Foreign Direct Investment}

In this section, we analyze the positive and normative implications of foreign direct investment by the comparative statics of the model. First, we begin with the case for an increase in the foreign country's real disposable income $y^{f}$.

From the maximization condition of a firm that belongs to industry $a$, the output for the foreign country proportionately increases with $f$. However, we must note that the foreign country's disposable income $y^{f}$ always appears as the product with the real exchange rate $e$ in market equilibrium conditions (18) and (21).

Accordingly, it is apparent that, regardless of the level of the foreign disposable income $y^{f}$, as long as the real exchange rate properly adjusts so that the product $e y^{f}$ is kept constant, there is no substantial effect on the domestic economy. This property implies that even if the foreign country upturns and provides the foreign-invested firm with additional business opportunities, such a possibility immediately disappears because of the appreciation of the real exchange rate. This appreciation is caused by the simultaneous moves of firms to transfer would-be profits to the home country. Thus, foreign direct investment never cultivates new business opportunities per se. This assertion is also clear from the fact that (22) does not contain the term ey ${ }^{f}$.

However, as seen in the second term of (21), which never appears without foreign direct investment, we can ascertain that there is a negative effect on the domestic effective demand. This is because foreign direct investment deprives the home country of the domestic employment opportunities and because a part of the effecttive demand flows to the foreign country as wage payments to foreign employees.

Thus, there emerges the coexistence of higher unemployment and continuous appreciation of the real exchange rate in an industrially hollowed country together with its surrounding economies' growth. Although such a tendency is observed in many advanced countries, it is especially prominent in Japan.

Next, let us analyze the welfare-economic implication of foreign direct investment. Since, from Equations (6) and (13), the net welfare gain is proportionate to the real total sales after deducting the real reservation wage payment, the total indirect utility is proportionate to the domestic real GNP $y^{h}$. (Note that the distribution ratio between the real reservation wage to residuals is $\eta^{-1}: 1-\eta^{-1}$.)

Accordingly, it is apparent from (21) that the equilibrium real GNP is always higher in the case without industrial hollowing. This is because, as previously discussed, a leak of the domestic effective demand, which comes from wage payments to the foreign country, exists. Thus, the industrial hollowing brings about a negative welfare effect for the home country. This tendency becomes more prominent as the monopolistic power of the tradable and mobile industry (industry $a$ ) declines, and $\eta^{-1}$ takes a lower value since such decline results in higher wage payments to foreign countries.

Hence, foreign direct investment under a flexible exchange rate system harms the economic welfare of the home country as a whole, although it is a rational behavior for individual firms. As such, an economic conflict emerges between the home country and internationalized individual firms.

Second, let us consider the effectiveness concerning the domestic fiscal-monetary policy. From (21), it is clear that the multiplier of our fiscal-monetary policy is smaller than in the case of a closed economy without foreign direct investment. That is,

$$
\frac{1}{1-c}>\frac{1}{1-\frac{1}{2}\left[c\left[1+\eta^{-1}\right]-\frac{[1-c]\left[1-\eta^{-1}\right]}{1-c+c \eta^{-1}}\right]}
$$

Such a decline in the effectiveness of aggregate management policies also comes from the fact that there is a leakage of the domestic effective demand via wage payment to the foreign country. Together with a weakening monopolistic power (lower value of $\eta^{-1}$ ), the decline in the power of fiscal-monetary policy becomes more serious. This is also because higher wage payments are required.

\section{Concluding Remarks}

This article analyzed macroeconomic effects concerning foreign direct investment in a small open country under a flexible exchange rate system with a rigorous dynamic microeconomic foundation. Obtained economic conesquences are not so optimistic for industrial hollowing.

First, industrial hollowing occurs whenever wage is cheaper than in the home country. Foreign direct investment is beneficial for each firm as long as the macroeconomic circumstances are kept intact despite of such a collective movement, which we call industrial hollowing. However, industrial hollowing under a flexible exchange 
rate is harmful to the home-country's economy. Massive transfer of earnings to the home country appreciates the real exchange rate enough to cancel out the spurious benefits from foreign direct investment.

There remains only the contraction of employment opportunities in the home country. The unemployment caused by industrial hollowing reduces the real effective demand and real disposable income via the multiplier effect. Thus, the economic welfare is deteriorated by industrial hollowing, as proved by Otaki [1]. In other words, there is a serious political conflict between a nation state and internationalized firms.

Second, the effectiveness of the fiscal-monetary policy, which is defined by the value of the fiscal multiplier, is weakened by industrial hollowing. Such a difficulty comes from the leakage of the effective demand that accompanies industrial hollowing. That is, the domestic effective demand leaks to the foreign country via the wage payments. It results in lowering the value of the fiscal multiplier. The decline in the power of the aggregate demand management should be taken into serious consideration whenever we think of the current severe constraint concerning fiscal discipline, although such a discussion is partly beyond the scope of this paper.

To summarize, libertarianism concerning foreign direct investment is never preferable. Some regulations based on common sense and coordination between the monetary authority and internationalized firms are urgently required.

\section{REFERENCES}

[1] M. Otaki, "A Welfare Economic Foundation for the FullEmployment Policy," Economics Letters, Vol. 102, No. 1, 2009, pp. 1-3. doi:10.1016/j.econlet.2008.08.003

[2] M. Otaki, "The Dynamically Extended Keynesian Cross and the Welfare-Improving Fiscal Policy," Economics Letters, Vol. 96, No. 1, 2007, pp. 23-29. doi:10.1016/j.econlet.2006.12.005

[3] M. Otaki, "A Pure Theory of Aggregate Price Determination," Theoretical Economics Letters, Vol. 1, No. 3, 2011, pp. 122-128. doi:10.4236/tel.2011.13026

[4] M. Otaki, "A Keynesian Model of a Small Open Economy under a Flexible Exchange Rate System," Theoretical Economics Letters, Forthcoming.

[5] R. E. Caves, "International Corporation: The Industrial Economics of Foreign Investment," Economica, Vol. 38, No. 149, 1971, pp. 1-27. doi:10.2307/2551748

[6] N. Hood and S. Young, "The Economics of Multinational Enterprise,” Longman, London, 1979.

[7] R. E. Caves, "Multinational Enterprise and Economic Analysis," Cambridge University Press, Cambridge, 1982.

[8] G. D. A. MacDougall, "The Benefits and Costs of Private Investment from Abroad: A Theoretical Approach," Economic Record, Vol. 36, No. 73, 1960, pp. 13-35. doi:10.1111/j.1475-4932.1960.tb00491.x

[9] M. C. Kemp, "The Pure Theory of International Trade," Prentice-Hall, Englewood Cliffs, 1964.

[10] R. F. Kahn, "The Relation of Home Invest to Unemployment," Economic Journal, Vol. 41, No. 162, 1931, pp. 173 198. doi: $10.2307 / 2223697$ 